\title{
Relationship between Muscular Fitness, Health Behaviors, and Health-related Quality of Life in U.S. Women
}

\author{
Peter D. Hart ${ }^{*}$ \\ Health Promotion Research, Havre, MT 59501 \\ *Corresponding author: pdhart@outlook.com
}

Received November 05, 2019; Revised December 14, 2019; Accepted December 23, 2019

\begin{abstract}
Background: Grip strength is a measure of muscular fitness and is related to many health problems in women. The primary purpose of this study was to examine the relationship between grip strength and HRQOL in U.S. women. A secondary purpose was to examine the extent to which physical activity (PA), obesity, and smoking moderate the grip strength and HRQOL relationship. Methods: Data for this research came from women 20 years of age and older participating in the 2013-2014 National Health and Nutrition Examination Survey (NHANES). Grip strength $(\mathrm{kg})$ was measured in both hands using a handgrip dynamometer and the largest reading across all trials served as the participant's score. HRQOL was assessed by a single question asking participants to rate their general health. Additionally, measures of body mass index (BMI), waist circumference (WC), moderate-to-vigorous physical activity (PA) (MVPA), TV time, sedentary time, and smoking were assessed. Multiple linear regression was used to model the relationship between HRQOL and grip strength while controlling for confounding variables. Results: Grip strength decreased proportionately in women with increasing age $(p<.001)$. Conversely, grip strength increased proportionately in women with increasing BMI $(p<.001)$. In the fully adjusted model, women with good HRQOL had greater grip strength (slope $=2.04 \mathrm{~kg}, S E=0.26, p<.001$ ) than their poor HRQOL counterparts. Additionally, HRQOL was significantly related to grip strength in women who were current smokers but not in those who were not current smokers. Conclusion: Results from this study indicate that grip strength and HRQOL are related in U.S. women. Furthermore, the grip strength and HRQOL relationship appears to remain in women who are current smokers.
\end{abstract}

Keywords: muscular fitness, health-related quality of life (HRQOL), women's health, epidemiology, NHANES

Cite This Article: Peter D. Hart, "Relationship between Muscular Fitness, Health Behaviors, and Health-related Quality of Life in U.S. Women.” American Journal of Sports Science and Medicine, vol. 8, no. 1 (2020): 1-7. doi: 10.12691/ajssm-8-1-1.

\section{Introduction}

Muscular fitness is a trait that considers both muscular strength and muscular endurance and relates to many health outcomes [1]. In studies involving women, muscular fitness has shown to be related to cardiovascular disease [2,3,4], cancer [5], metabolic syndrome [6,7], depression [8,9], falls [10], cognitive function [11,12], and obesity [13]. Health-related quality of life (HRQOL) is an outcome measure of growing interest and is generally considered an important indicator of the impact a person's health has on their quality of life [14]. Studies have investigated the relationship between muscular strength and HRQOL using both cross-sectional [15,16] and longitudinal $[17,18]$ designs. However, little evidence exists on this relationship in a representative sample of U.S. women. Therefore, the purpose of this study was to examine the relationship between grip strength and HRQOL among U.S. women. A secondary purpose was to examine the extent to which physical activity (PA), obesity, and smoking moderate the grip strength and HRQOL relationship.

\section{Methods}

\subsection{Study Design}

Data for this research came from females 20+ years of age participating in the 2013-2014 National Health and Nutrition Examination Survey (NHANES) [19]. NHANES is a continuous survey designed to assess health behavior, health status, and nutrition of noninstitutionalized civilian residents of the U.S. NHANES collects data on individuals using personal interviews, standardized physical examinations, and laboratory tests. The current study used data only from personal interviews and physical examinations. The sample in the current study consisted of women with complete grip strength and HRQOL data. 


\subsection{Variables Utilized}

The dependent variable in this study was grip strength. The main independent variable was HRQOL. Moderating variables were binary variables indicating obesity status, meeting PA guidelines status, and current smoking status. Other variables used in this study were body mass index (BMI), waist circumference (WC), moderate-to-vigorous PA (MVPA), TV time, sedentary time, age, race, marital/partner status, income, and education.

\subsection{Assessment of Grip Strength and HRQOL}

HRQOL was assessed by a single question asking participants to rate their general health [20]. In this study, women rating their health as "good”, "very good", or "excellent" were considered to have good HRQOL whereas those rating it "fair" or "poor" were considered to have poor HRQOL. Grip strength $(\mathrm{kg})$ was measured in both hands using a handgrip dynamometer administered by a trained examiner [21]. After a submaximal practice trial and grip adjustment, participants squeezed the dynamometer as hard as possible with a randomly selected hand while in the standing position. The test was then completed with the other hand for a total of three trials on each hand. The largest dynamometer reading across all trials served as the grip strength score in this study.

\subsection{Assessment of PA Variables}

A continuous PA variable was computed from constructed variables of minutes of moderate physical activity (MPA) per week and minutes of vigorous physical activity (VPA) per week [22]. VPA was assessed from the responses to two questions. The first question asked respondents how many days they participated in vigorous intensity sports, fitness, or recreational activities. The second question asked respondents how much time they spend doing vigorous-intensity activity on a typical day. Multiplying days with minutes yielded minutes of VPA per week. The same two questions were asked regarding moderate-intensity activities to assess MPA per week. These two physical activity variables were then used to compute minutes of MVPA per week. A second PA variable was computed from MVPA which consisted of two discrete PA groups: $(1)<150$ minutes of MVPA and (2) 150+ minutes of MVPA. TV time was assessed from a survey question asking participants how many hours per day they sat and watched TV or videos during the past 30 days [22]. For this study, two discrete TV time groups were formed: (1) $<5$ hours and (2) 5+ hours. Sedentary time was assessed from a question asking participants how much time they usually spend sitting in a typical day [22]. For this study, sedentary time was converted to quartiles, where the first quartile contained the least sedentary individuals and the last quartile contained the most sedentary.

\subsection{Assessment of Body Composition Variables}

Using WC, female participants were categorized into two discrete groups: 1) obese (WC: $>88 \mathrm{~cm}$ ) and non-obese (WC: $\leq 88 \mathrm{~cm}$ ). The categorization of WC was used as the obese status variable. Using BMI $\left(\mathrm{kg} / \mathrm{m}^{2}\right)$, participants were categorized into one of four discrete groups: 1) underweight (BMI: < 18.5), normal weight (BMI: 18.5 to 24.9), overweight (BMI: 25.0 to 29.9), and obese (BMI: 30+). Measurements for both BMI (height and weight) and WC were collected by trained NHANES health professionals during a medical examination [23].

\subsection{Other Variables}

A smoking status variable was constructed from a question asking participants if they now smoke cigarettes [24]. Those responding "yes, every day" or "yes, some days" were considered current smokers and those responding "no, not at all" were considered non-current smokers. Demographic variables used in this study were age (20-24 yr, 25-34 yr, 35-44 yr, 45-54 yr, 55-64 yr, 65+ yr), race/ethnicity (White, Black, Hispanic, Other), household income (\$0-\$19.999, \$20,000-\$44,999, \$45,000-\$64,999, $\$ 65,000-\$ 74,999, \$ 75,000+$ ), education (no high school diploma, high school diploma, some college, 4-year college degree), and marital/partner status (living with a spouse/partner, not living with spouse/partner).

\subsection{Statistical Analyses}

Descriptive statistics were computed on grip strength values across HRQOL groups with associated independent t-tests. Tests of linear trend in grip strength were conducted across ordinal variables and analysis of variance (ANOVA) tests conducted across nominal variables. Follow-up mean comparisons with TukeyKramer adjustments were made across all groups when the omnibus test was significant and group levels were greater than 2. Multiple linear regression analysis of grip strength regressed on HRQOL was conducted at three different levels. First, regression models were age-adjusted (Model I). Second, regression models were adjusted for age, race/ethnicity, marital/partner status, income, and education (Model II). Lastly, regression models were adjusted for age, race/ethnicity, marital/partner status, income, education, MVPA, sedentary time, and BMI (Model III). Additionally, three other sets of regression models were run to examine moderator effects (obese, PA, and smoking). All analyses were performed using the survey procedures of SAS version $9.4[25,26,27]$. The CORRPLOT package of $\mathrm{R}$ was used for graphics [28]. All $p$-values were reported as 2-sided and statistical significance was defined as $p$-values $<0.05$.

\section{Results}

Table 1 contains descriptive statistics on grip strength values by HRQOL across demographic groups. Overall, women reporting poor HRQOL had significantly lower grip strength than women reporting good HRQOL, Mean (SE): 27.4(0.26) vs. 29.9(0.17), $p<.001$. Additionally, a significant $(p s<.001)$ linear trend in grip strength across age groups was seen in both HRQOL groups, with strength decreasing as age increased. Furthermore, for women 35 years of age and older, grip strength was 
significantly $(p s<.05)$ greater if reporting good HRQOL as compared to poor HRQOL. Race/ethnicity was a significant factor related to grip strength, however, only in those reporting good HRQOL. Black women reporting good HRQOL had significantly $\left(p \mathrm{~s}_{\text {adjusted }}<.05\right)$ greater strength than all other race/ethnicity groups. Finally, women with at least some college education had significantly $\left(p \mathrm{~s}_{\text {adjusted }}<.05\right)$ greater grip strength than women without a high school diploma.

Table 2 contains descriptive statistics on grip strength values by HRQOL across health characteristic groups. All health subgroups saw significantly $(p s<.05)$ greater grip strength among women reporting good HRQOL as compared to those reporting poor HRQOL. Additionally, a significant $(p s<.001)$ linear trend in grip strength across BMI groups was seen in both HRQOL groups, with strength increasing as BMI increased. Lastly, a modest yet significant $(p s<.001)$ linear trend in grip strength across sedentary time quartiles was seen in both HRQOL groups, with strength decreasing as sedentary time increased.

Figure 1 contains a correlation matrix plot of all study variables, where the size of the circles represents the strength of correlation and the shade (e.g., darker) represents the direction (e.g., negative). All correlations (circles) shown in Figure 1 were significant $(p s<.05)$ with blank cells representing a non-significant correlation. The most noteworthy result from this matrix showed that grip strength was significantly $(p s<.05)$ related to all study variables. Furthermore, the largest grip strength correlations were seen with BMI, HRQOL, and age.

Table 3 displays results from the multiple linear regression analysis of grip strength regressed on HRQOL. In the age-adjusted model, women with good HRQOL had greater grip strength $($ slope $=1.83 \mathrm{~kg}, S E=0.24, p<.001$ ) than their poor HRQOL counterparts. Adjusting for demographic (slope $=1.58 \mathrm{~kg}, S E=0.32, p<.001$ ) and health (slope $=2.04 \mathrm{~kg}, S E=0.26, p<.001$ ) characteristics did not change the significance of the relationship. Furthermore, analyses across moderator variables showed a similar trend, with exception for smoking status. That is, in fully adjusted models, HRQOL was significantly related to grip strength in women who were current smokers (slope $=1.72$ $\mathrm{kg}, S E=0.46, p=.002$ ) but not in those who were not current smokers (slope $=0.44 \mathrm{~kg}, S E=0.88, p=.623$ ).

Table 1. Descriptive values of grip strength by HRQOL across demographic characteristics, U.S. women 20+ years of age 2013-2014

\begin{tabular}{|c|c|c|c|c|c|c|c|}
\hline \multirow[b]{2}{*}{ Characteristic } & \multicolumn{3}{|c|}{ Good HRQOL } & \multicolumn{3}{|c|}{ Poor HRQOL } & \multirow[b]{2}{*}{$p$} \\
\hline & Mean & $S E$ & $t$ & Mean & $S E$ & $t$ & \\
\hline Overall & 29.92 & 0.17 & & 27.44 & 0.26 & & $<.001$ \\
\hline \multicolumn{8}{|l|}{ Age group (yr) } \\
\hline $20-24$ & 31.42 & 0.55 & $\mathrm{a}$ & 31.70 & 0.97 & $\mathrm{a}$ & .771 \\
\hline $25-34$ & 32.17 & 0.31 & b & 32.09 & 0.71 & b & .923 \\
\hline $35-44$ & 32.40 & 0.30 & c & 29.80 & 0.56 & c & .002 \\
\hline $45-54$ & 31.51 & 0.34 & d & 29.21 & 0.55 & d & .007 \\
\hline $55-64$ & 28.56 & 0.32 & a,b,c,d & 26.00 & 0.80 & a,b,c & .012 \\
\hline $65^{+}$ & 24.45 & 0.33 & a,b,c,d & 21.43 & 0.54 & $a, b, c, d$ & $<.001$ \\
\hline$p$ for trend & & & $<.001$ & & & $<.001$ & \\
\hline \multicolumn{8}{|l|}{ Race/Ethnicity } \\
\hline White & 29.58 & 0.20 & $\mathrm{a}$ & 26.57 & 0.37 & $\mathrm{a}, \mathrm{b}$ & $<.001$ \\
\hline Black & 33.23 & 0.39 & a,b,c & 29.79 & 0.76 & $\mathrm{a}, \mathrm{c}$ & .001 \\
\hline Hispanic & 29.84 & 0.31 & $\mathrm{~b}$ & 28.06 & 0.30 & $\mathrm{~b}$ & $<.001$ \\
\hline Other & 28.45 & 0.43 & c & 27.02 & 0.88 & c & .169 \\
\hline$p$ for overall diff & & & $<.001$ & & & .107 & \\
\hline \multicolumn{8}{|l|}{ Income (US \$) } \\
\hline $0-19,999$ & 29.01 & 0.50 & & 26.20 & 0.64 & & $<.001$ \\
\hline $20,000-44,999$ & 29.22 & 0.31 & & 28.37 & 0.50 & & .127 \\
\hline $45,000-64,999$ & 31.00 & 0.47 & & 28.61 & 0.86 & & .042 \\
\hline $65,000-74,999$ & 30.99 & 0.71 & & 28.81 & 1.50 & & .148 \\
\hline $75,000+$ & 30.13 & 0.21 & & 26.71 & 0.96 & & .003 \\
\hline$p$ for trend & & & .056 & & & .054 & \\
\hline \multicolumn{8}{|l|}{ Education } \\
\hline No high school diploma & 28.46 & 0.36 & a,b & 27.23 & 0.81 & & .114 \\
\hline High school diploma & 29.51 & 0.35 & & 27.54 & 0.67 & & .017 \\
\hline Some college & 30.57 & 0.26 & $\mathrm{a}$ & 28.11 & 0.60 & & .003 \\
\hline 4-year college degree & 29.91 & 0.22 & $b$ & 25.21 & 1.30 & & .004 \\
\hline$p$ for trend & & & $<.001$ & & & .374 & \\
\hline \multicolumn{8}{|l|}{ Living with spouse/partner } \\
\hline Yes & 30.18 & 0.19 & & 27.79 & 0.26 & & $<.001$ \\
\hline No & 29.53 & 0.32 & & 27.06 & 0.36 & & $<.001$ \\
\hline$p$ for overall diff & & & .111 & & & .059 & \\
\hline
\end{tabular}

Note. Grip strength values are in kilograms (kg). $p$-values in bold are significant at the .05 level. $t$ column represents tests of within group differences with Tukey-Kramer adjustment where groups with same letter are significantly different. 
Table 2. Descriptive values of grip strength by HRQOL across health characteristics, U.S. women 20+ years of age 2013-2014

\begin{tabular}{|c|c|c|c|c|c|c|c|}
\hline \multirow[b]{2}{*}{ Characteristic } & \multicolumn{3}{|c|}{ Good HRQOL } & \multicolumn{3}{|c|}{ Poor HRQOL } & \multirow[b]{2}{*}{$p$} \\
\hline & Mean & $S E$ & $t$ & Mean & $S E$ & $t$ & \\
\hline \multicolumn{8}{|l|}{ BMI group } \\
\hline Underweight & 26.54 & 1.28 & $\mathrm{a}$ & 22.03 & 3.03 & & $<.001$ \\
\hline Normal weight & 28.94 & 0.30 & $\mathrm{~b}$ & 24.91 & 0.75 & a & $<.001$ \\
\hline Overweight & 29.79 & 0.29 & c & 26.64 & 0.81 & & .002 \\
\hline Obese & 31.19 & 0.33 & a,b,c & 28.69 & 0.39 & $\mathrm{a}$ & $<.001$ \\
\hline$p$ for trend & & & $<.001$ & & & $<.001$ & \\
\hline \multicolumn{8}{|l|}{ WC group } \\
\hline Obese & 30.41 & 0.21 & & 28.10 & 0.24 & & $<.001$ \\
\hline Not obese & 29.30 & 0.25 & & 25.60 & 0.74 & & $<.001$ \\
\hline$p$ for diff & & & .004 & & & .005 & \\
\hline \multicolumn{8}{|l|}{ Met PA Guidelines } \\
\hline No & 29.61 & 0.25 & & 27.36 & 0.31 & & $<.001$ \\
\hline Yes & 30.40 & 0.18 & & 27.94 & 0.74 & & $<.001$ \\
\hline$p$ for diff & & & .002 & & & .521 & \\
\hline \multicolumn{8}{|l|}{ TV time (per day) } \\
\hline$<5$ hours & 30.08 & 0.16 & & 28.10 & 0.27 & & $<.001$ \\
\hline $5+$ hours & 28.70 & 0.72 & & 25.80 & 0.47 & & .001 \\
\hline$p$ for diff & & & .076 & & & $<.001$ & \\
\hline \multicolumn{8}{|l|}{ Sedentary time (quartiles) } \\
\hline Q1 (least sedentary) & 30.56 & 0.23 & $\mathrm{a}$ & 29.14 & 0.42 & a & .006 \\
\hline Q2 & 29.60 & 0.26 & $\mathrm{a}$ & 27.84 & 0.52 & & .007 \\
\hline Q3 & 29.84 & 0.32 & & 25.74 & 0.98 & a & .002 \\
\hline Q4 (most sedentary) & 29.69 & 0.32 & & 27.45 & 0.70 & & .003 \\
\hline$p$ for trend & & & .010 & & & .004 & \\
\hline \multicolumn{8}{|l|}{ Current smoker } \\
\hline No & 28.94 & 0.43 & & 26.93 & 0.76 & & $<.001$ \\
\hline Yes & 31.24 & 0.34 & & 28.62 & 0.33 & & $<.001$ \\
\hline$p$ for diff & & & .003 & & & .021 & \\
\hline
\end{tabular}

Note. Grip strength values are in kilograms $(\mathrm{kg})$. $p$-values in bold are significant at the .05 level. $t$ column represents tests of within group differences with Tukey-Kramer adjustment where groups with same letter are significantly different.

Table 3. Multiple linear regression analysis of grip strength regressed on HRQOL, U.S. women 20+ years of age 2013-2014

\begin{tabular}{|c|c|c|c|c|c|c|c|c|c|}
\hline \multirow[b]{2}{*}{ Characteristic } & \multicolumn{3}{|c|}{ Model I } & \multicolumn{3}{|c|}{ Model II } & \multicolumn{3}{|c|}{ Model III } \\
\hline & Estimate & $S E$ & $p$ & Estimate & $S E$ & $p$ & Estimate & SE & $p$ \\
\hline \multicolumn{10}{|l|}{ Overall } \\
\hline Poor HRQOL & reference & & & reference & & & reference & & \\
\hline Good HRQOL & 1.83 & 0.24 & $<.001$ & 1.58 & 0.32 & $<.001$ & 2.04 & 0.26 & $<.001$ \\
\hline \multicolumn{10}{|c|}{ Did meet PA Guidelines } \\
\hline Poor HRQOL & reference & & & reference & & & reference & & \\
\hline Good HRQOL & 2.00 & 0.50 & .001 & 1.59 & 0.57 & .013 & 2.27 & 0.55 & $<.001$ \\
\hline \multicolumn{10}{|c|}{ Did not meet PA Guidelines } \\
\hline Poor HRQOL & reference & & & reference & & & reference & & \\
\hline Good HRQOL & 1.74 & 0.29 & $<.001$ & 1.51 & 0.37 & $<.001$ & 1.89 & 0.33 & $<.001$ \\
\hline \multicolumn{10}{|l|}{ Obese } \\
\hline Poor HRQOL & reference & & & reference & & & reference & & \\
\hline Good HRQOL & 2.03 & 0.26 & $<.001$ & 1.80 & 0.35 & $<.001$ & 1.59 & 0.32 & $<.001$ \\
\hline \multicolumn{10}{|l|}{ Non-obese } \\
\hline Poor HRQOL & reference & & & reference & & & reference & & \\
\hline Good HRQOL & 3.02 & 0.72 & $<.001$ & 2.15 & 0.81 & .017 & 2.05 & 0.85 & .029 \\
\hline \multicolumn{10}{|l|}{ Is a current smoker } \\
\hline Poor HRQOL & reference & & & reference & & & reference & & \\
\hline Good HRQOL & 1.90 & 0.46 & $<.001$ & 1.69 & 0.49 & .004 & 1.72 & 0.46 & .002 \\
\hline \multicolumn{10}{|c|}{ Is not a current smoker } \\
\hline Poor HRQOL & reference & & & reference & & & reference & & \\
\hline Good HRQOL & 0.95 & 0.74 & .220 & 0.65 & 0.85 & .455 & 0.44 & 0.88 & .623 \\
\hline
\end{tabular}

Note. -values in bold are significant at the .05 level. Model estimates are in kilograms (kg). Model I is age adjusted. Model II is age, race, marital/partner status, income, and education adjusted. Model III is adjusted as model II but additionally MVPA, sedentary time, and BMI adjusted, when appropriate. Obese status was defined as a WC $>88 \mathrm{~cm}$. Meeting PA guidelines was defined as self-reporting 150+ minutes of moderate-tovigorous-intensity recreational PA per week. 


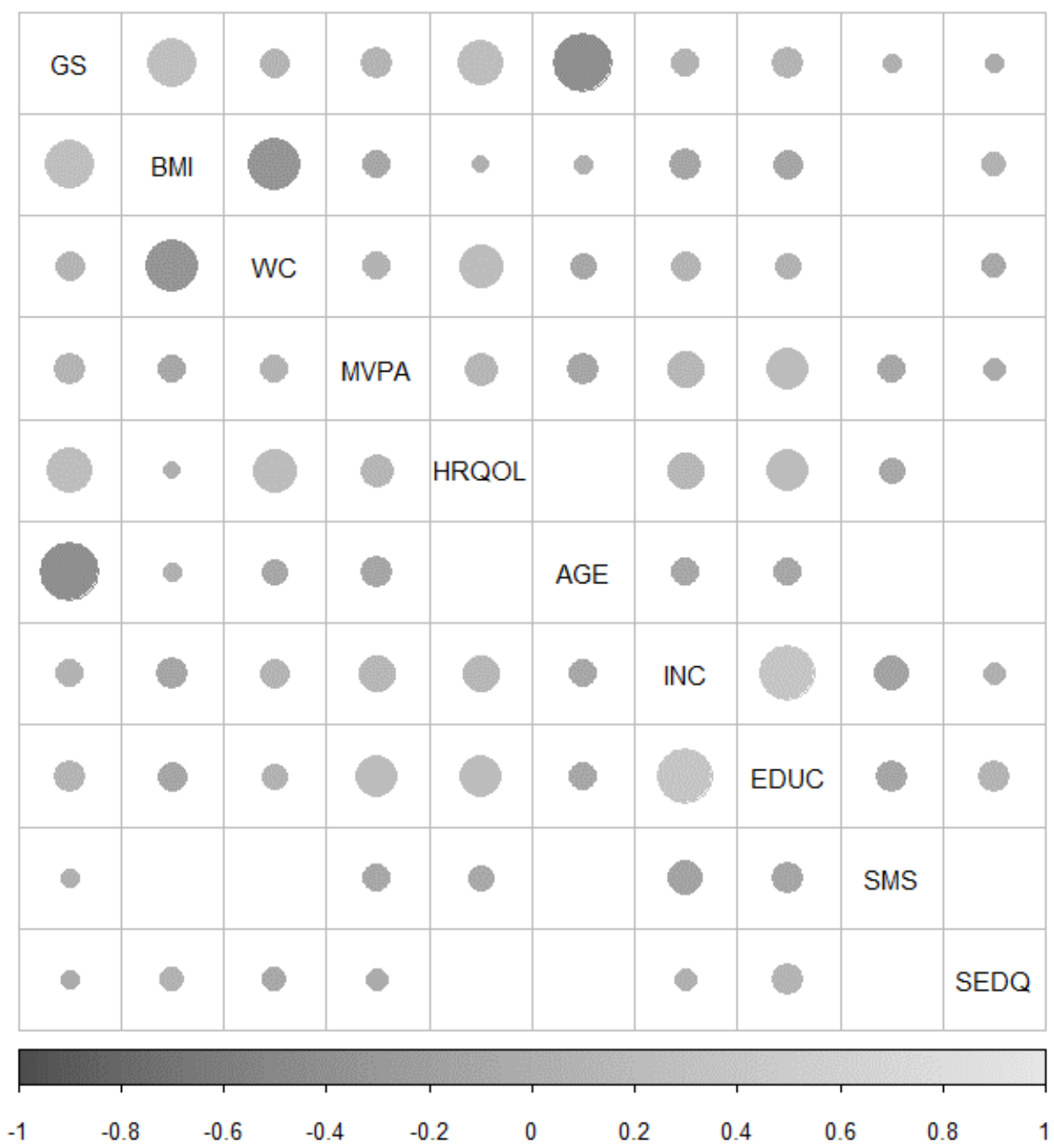

Note. GS is grip strength. BMI is body mass index. WC is waist circumference. MVPA is moderate-to-vigorous physical activity. HRQOL is health-related quality of life. AGE is age. INC is household income. EDUC is education level. SMS is smoking status. SEDQ is sedentary time quartile. All cells with circles indicate a significant $(p<.05)$ correlation coefficient.

Figure 1. Correlation matrix of study variables

\section{Discussion}

The primary purpose of this study was to examine the relationship between muscular fitness (grip strength) and HRQOL in a representative sample of U.S. women. Results support HRQOL as a predictor of grip strength in women, with better HRQOL indicative of greater muscular strength. Furthermore, this relationship endured after rigorous adjustment for possible confounding variables. Therefore, this study presents evidence that surpasses previously mentioned studies [15-18] in that it supports the muscular fitness and HRQOL relationship among all non-institutionalized U.S. women.

A secondary purpose of this study was to examine the moderating effects of PA, obesity, and smoking status on the grip strength and HRQOL relationship. This portion of the study showed conflicting results. For example, analyses by both PA and obese factors, indicated no differences in the muscular strength and HRQOL relationship. That is, HRQOL was a statistical predictor of strength regardless of PA or obesity status. However, analyses across smoking status indicated a difference in this relationship. Namely, among women who currently smoked, HRQOL was a statistical predictor of muscular strength. Conversely, among women who did not currently smoke, the HRQOL and muscular strength relationship was diminished to a non-significant level. For the former significant scenario, these findings may in part be explained by the HRQOL construct itself. That is, among smokers, there are likely women who maintain an otherwise healthy lifestyle and who rate their overall HRQOL as good and consequently have adequate muscular fitness. On the other hand, among smokers, there are likely women who maintain an unhealthy lifestyle and rate their general HRQOL as poor and consequently have inadequate muscular fitness. Said differently, HRQOL as a construct may be able to detect group differences in health status with more specificity in a smoking population than in a healthier population [29,30]. Therefore, these results additionally stipulate that HRQOL may be a valid predictor of muscular fitness in relatively unhealthy populations, such as women who smoke.

The following strengths of this research should be discussed. One strength of this study was its use of an 
objective measure of muscular fitness. The use of a dynamometer-derived grip strength measure added strong measurement properties to the assessment of the study's dependent variable [31,32]. Another strength of this study was its use of a nationally representative sample of women. NHANES data represent all noninstitutionalized civilian U.S. individuals residing in the 50 states and District of Columbia [33]. Therefore, results from this study can be generalized to all noninstitutionalized U.S. adult females $20+$ years of age.

The limitations of this research should also be discussed. The most serious limitation in this study is the cross-sectional nature of the NHANES study design. It should be stated that evidence from cross-sectional data do not provide cause-and-effect evidence. That is, results from this study do not support the notion that HRQOL causes muscular strength. Results from this study should be considered as correlational only. Another limitation of this study was the self-report assessment of HRQOL and PA. More specifically, self-report questionnaires have certain biases over more objective means of measurement. Given this bias, the HRQOL item used in this study has shown to have adequate psychometric properties [34,35]. As well, the items used to assess PA in this study also have adequate psychometric properties supporting their use in this population [36,37].

\section{Conclusions}

Results from this study indicate that muscular fitness and HRQOL are related in U.S. women. The muscular fitness and HRQOL relationship appears to remain in women regardless if they meet PA guidelines and regardless of their obesity status. However, the muscular fitness and HRQOL relationship appears to exist in women who are current smokers and not in women who are not current smokers. Health promotion efforts directed toward improving HRQOL may also find benefits of improved muscular fitness in U.S. women.

\section{Acknowledgements}

No financial assistance was used to assist with this project.

\section{References}

[1] Garber CE, Blissmer B, Deschenes MR, Franklin BA, Lamonte MJ, Lee IM, Nieman DC, Swain DP. American College of Sports Medicine position stand. Quantity and quality of exercise for developing and maintaining cardiorespiratory, musculoskeletal, and neuromotor fitness in apparently healthy adults: guidance for prescribing exercise. Medicine and science in sports and exercise. 2011 Jul; 43(7): 1334-59.

[2] Celis-Morales CA, Petermann F, Hui L, Lyall DM, Iliodromiti S, McLaren J, Anderson J, Welsh P, Mackay DF, Pell JP, Sattar N. Associations between diabetes and both cardiovascular disease and all-cause mortality are modified by grip strength: Evidence from UK Biobank, a prospective population-based cohort study. Diabetes care. 2017 Oct 6: dc170921.

[3] Kim Y, Wijndaele K, Lee DC, Sharp SJ, Wareham N, Brage S. Independent and joint associations of grip strength and adiposity with all-cause and cardiovascular disease mortality in 403,199 adults: the UK Biobank study. The American journal of clinical nutrition. 2017 Aug 9; 106(3): 773-82.

[4] Wu Y, Wang W, Liu T, Zhang D. Association of grip strength with risk of all-cause mortality, cardiovascular diseases, and cancer in community-dwelling populations: a meta-analysis of prospective cohort studies. Journal of the American Medical Directors Association. 2017 Jun 1; 18(6): 551-e17.

[5] Celis-Morales CA, Welsh P, Lyall DM, Steell L, Petermann F, Anderson J, Iliodromiti S, Sillars A, Graham N, Mackay DF, Pell JP. Associations of grip strength with cardiovascular, respiratory, and cancer outcomes and all-cause mortality: prospective cohort study of half a million UK Biobank participants. BMJ. 2018 May 8; 361: k1651

[6] Sayer AA, Syddall HE, Dennison EM, Martin HJ, Phillips DI, Cooper C, Byrne CD. Grip strength and the metabolic syndrome: findings from the Hertfordshire Cohort Study. QJM: An International Journal of Medicine. 2007 Nov 1; 100(11): 707-13.

[7] Wijndaele K, Duvigneaud N, Matton L, Duquet W, Thomis M, Beunen G, Lefevre J, Philippaerts RM. Muscular strength, aerobic fitness, and metabolic syndrome risk in Flemish adults. Medicine and science in sports and exercise. 2007 Feb 1; 39(2): 233.

[8] Lee MR, Jung SM, Bang H, Kim HS, Kim YB. The association between muscular strength and depression in Korean adults: a cross-sectional analysis of the sixth Korea National Health and Nutrition Examination Survey (KNHANES VI) 2014. BMC public health. 2018 Dec; 18(1): 1123.

[9] McDowell CP, Gordon BR, Herring MP. Sex-related differences in the association between grip strength and depression: Results from the Irish Longitudinal Study on Ageing. Experimental gerontology. 2018 Apr 1; 104: 147-52.

[10] Tsuyuguchi R, Kurose S, Seto T, Takao N, Tagashira S, Tsutsumi H, Otsuki S, Kimura Y. Toe grip strength in middle-aged individuals as a risk factor for falls. The Journal of sports medicine and physical fitness. 2018 Sep; 58(9): 1325-30.

[11] Yang L, Koyanagi A, Smith L, Hu L, Colditz GA, Toriola AT, Sánchez GF, Vancampfort D, Hamer M, Stubbs B, Waldhör T. Hand grip strength and cognitive function among elderly cancer survivors. PloS one. 2018 Jun 4; 13(6): e0197909.

[12] Sternäng O, Reynolds CA, Finkel D, Ernsth-Bravell M, Pedersen NL, Dahl Aslan AK. Grip strength and cognitive abilities: associations in old age. Journals of Gerontology Series B: Psychological Sciences and Social Sciences. 2015 Mar 18; 71(5): 841-8.

[13] Zoico E, Di Francesco V, Guralnik JM, Mazzali G, Bortolani A, Guariento S, Sergi G, Bosello O, Zamboni M. Physical disability and muscular strength in relation to obesity and different body composition indexes in a sample of healthy elderly women. International journal of obesity. 2004 Feb; 28(2): 234.

[14] US Department of Health and Human Services. Healthy People 2020. Washington, DC.

[15] Musalek C, Kirchengast S. Grip Strength as an Indicator of Health-Related Quality of Life in Old Age-A Pilot Study. International journal of environmental research and public health. 2017 Nov 24; 14(12): 1447.

[16] Sayer AA, Syddall HE, Martin HJ, Dennison EM, Roberts HC, Cooper C. Is grip strength associated with health-related quality of life? Findings from the Hertfordshire Cohort Study. Age and ageing. 2006 May 11; 35(4): 409-15.

[17] Cheema BS, Chan D, Fahey P, Atlantis E. Effect of progressive resistance training on measures of skeletal muscle hypertrophy, muscular strength and health-related quality of life in patients with chronic kidney disease: a systematic review and meta-analysis. Sports Medicine. 2014 Aug 1; 44(8): 1125-38.

[18] Katula JA, Rejeski WJ, Marsh AP. Enhancing quality of life in older adults: a comparison of muscular strength and power training. Health and Quality of Life Outcomes. 2008 Dec; 6(1): 45

[19] Centers for Disease Control and Prevention. National Center for Health Statistics. National Health and Nutrition Examination Survey: Plan and Operations, 1999-2010: https://wwwn.cdc.gov/nchs/nhanes/analyticguidelines.aspx

[20] Centers for Disease Control and Prevention National Center for Health Statistics. NHANES 2013-2014 Current Health Status HSQ; 2013

[21] Centers for Disease Control and Prevention National Center for Health Statistics. NHANES 2013-2014 Muscle Strength Procedures Manual; 2013. 
[22] Centers for Disease Control and Prevention National Center for Health Statistics. NHANES 2013-2014 Physical Activity And Physical Fitness - PAQ; 2013.

[23] Centers for Disease Control and Prevention National Center for Health Statistics. NHANES 2013-2014 Anthropometry Procedures Manual; 2013.

[24] Centers for Disease Control and Prevention National Center for Health Statistics. NHANES 2013-2014 Smoking and Tobacco Use - SMQ; 2013.

[25] Cody, R. P., \& Smith, J. K. (2006). Applied Statistics \& SAS Programming. Prentice Hall.

[26] Allison, P. D. (1999). Multiple regression: A primer. Pine Forge Press.

[27] Lewis, T. H. (2016). Complex survey data analysis with SAS. Chapman and Hall/CRC.

[28] Wei T, Simko V, Levy M, Xie Y, Jin Y, Zemla J. Package 'corrplot'. Statistician. 2017 Oct 16; 56: 316-24.

[29] Hart PD, Kang M, Weatherby NL, Lee YS, Brinthaupt TM. Evaluation of the Short-Form Health Survey (SF-36) Using the Rasch Model. American Journal of Public Health Research. 2015; 3(4): 136-47.

[30] Hart PD. Assessment of health-related quality of life in rural population health research: using classical and modern psychometric approaches. World J Prev Med. 2015; 3(2): 44e7.
[31] Clifford MS, Hamer P, Phillips M, Wood FM, Edgar DW. Grip strength dynamometry: Reliability and validity for adults with upper limb burns. Burns. 2013 Nov 1; 39(7): 1430-6.

[32] Bellace JV, Healy D, Besser MP, Byron T, Hohman L. Validity of the Dexter Evaluation System's Jamar dynamometer attachment for assessment of hand grip strength in a normal population. Journal of hand therapy. 2000 Jan 1; 13(1): 46-51.

[33] Johnson, C. L., Dohrmann, S. M., Burt, V., \& Mohadjer, L. K. (2014). National health and nutrition examination survey: sample design, 2011-2014.

[34] Barile, J.P., Horner-Johnson, W., Krahn, G., Zack, M., Miranda, D., DeMichele, K., Ford, D. and Thompson, W.W. (2016). Measurement characteristics for two health-related quality of life measures in older adults: The SF-36 and the CDC Healthy Days items. Disability and health journal, 9(4), 567-574.

[35] Cunny, K. A., \& Perri III, M. (1991). Single-item vs multiple-item measures of health-related quality of life. Psychological reports, 69(1), 127-130.

[36] Moreira, A. D., Claro, R. M., Felisbino-Mendes, M. S., \& Velasquez-Melendez, G. (2017). Validity and reliability of a telephone survey of physical activity in Brazil. Revista Brasileira de Epidemiologia, 20(1), 136-146.

[37] Chu, A. H., Ng, S. H., Koh, D., \& Müller-Riemenschneider, F. (2015). Reliability and validity of the self-and intervieweradministered versions of the Global Physical Activity Questionnaire (GPAQ). PLoS One, 10(9), e0136944. 